Original Article

\title{
Effects of shoulder reaching exercise on the balance of patients with hemiplegia after stroke
}

\author{
SAng-Mi Chung, PhD, OT ${ }^{1)}$, Kyoung-Bo Lee, PhD, PT ${ }^{2)}$, Young-Dong Kim, DPT, PT $^{3 \text { )* }}$ \\ 1) Department of Occupational Therapy, Sangii Youngseo University, Republic of Korea \\ 2) Department of Rehabilitation Medicine, St. Vincent's Hospital, College of Medicine, The Catholic \\ University of Korea, Republic of Korea \\ 3) Human Movement Research: 497 Wolpyeong-dong, Seo-gu, Daejeon 302-281, Republic of Korea
}

\begin{abstract}
Purpose] This study investigated whether a shoulder reaching exercise was beneficial for restoring the standing balance of patients with hemiplegia after stroke. [Subjects and Methods] There were 13 subjects in the experimental group (EG) and 14 subjects in the control group (CG), all with hemiplegia following stroke. The shoulder reaching exercise intervention was performed by the EG and conventional physical therapy was administered to the CG for 30 minutes, 3 times a week for 4 weeks. Virtual reality (RM, BioRescue -AP 1153, France) was used as an assessment tool. All data were analyzed using SPSS version 18 (Statistical Package for the Social Science). [Results] After the intervention, the EG showed significant differences in the distances moved in the anteroposterior and mediolateral directions. The length and velocity were reduced after the intervention in both the EG and the CG. There were significant differences in the distances moved in the north, south and west directions between the groups. The sway path lengths of the subjects in the Romberg test were reduced under both the eyes open and closed conditions in the EG. There was no significant variation in sway velocity in the EG and the CG. [Conclusion] The shoulder reaching exercise had beneficial effects on the distances moved in the anteroposterior and mediolateral directions. Key words: Balance, Scapula, Stroke
\end{abstract}

(This article was submitted Feb. 22, 2016, and was accepted Apr. 7, 2016)

\section{INTRODUCTION}

An impaired shoulder complex is a common problem for patients with hemiplegia, because muscles in the affected arm tend to be weakened. Shoulder subluxation and pain, secondary impairments of the upper motor neuron lesion, influence a variety of the upper limb functions ${ }^{1}$. The most distal regions often have severe hemiparesis in the upper extremity. Even though proximal muscles and joints are the least affected, intended movement with precise proximal segment control is slow, awkward and uncoordinated. Interventions for hemiplegic patients focus not on gross motor skills of the proximal limbs, but on the fine motor skills of the distal limbs, even though scapular movement is generally impaired ${ }^{2}$. Scapular orientation of the affected arm can be changed due to muscle weakness in the arm, and generally, subjects with this problem can not preserve their anatomical characteristics or raise the arm properly. Increased motor dysfunction in the upper extremities is related to weakness of the scapular stabilizers and affects independent daily living ${ }^{3}$. In addition, the postural alignment of the patients with hemiplegia after stroke can be altered in standing compared to subjects without neurological problems. Postural alignment is the relationship of the center of gravity to the body parts. A complex process of controlled mobility and skilled activity is needed for postural stability, which is a fundamental prerequisite for advanced motor control ${ }^{4)}$. The main goal for patients after stroke is to gain the ability to stand and walk by themselves. Because standing and walking need complex mechanisms of postural control, postural control deficits have been treated with diverse strategies ${ }^{5)}$. Therefore, this study examined a new intervention, which is performed with an active scapular movement in a proper scapular setting for regaining overall postural control in standing.

\footnotetext{
*Corresponding author. Young-dong Kim (E-mail: exptkyd@daum.net)

(C)2016 The Society of Physical Therapy Science. Published by IPEC Inc.

This is an open-access article distributed under the terms of the Creative Commons Attribution Non-Commercial No Derivatives (by-nc-nd) License $<$ http://creativecommons.org/licenses/by-nc-nd/4.0/>.
} 
Table 1. General characteristics $(\mathrm{N}=27)$

\begin{tabular}{llcc}
\hline & & EG & CG \\
\hline \multirow{2}{*}{ Gender } & Male & 7 & 7 \\
& Female & 7 & 6 \\
\multirow{2}{*}{ Lesion } & Infarction & 11 & 10 \\
\multirow{2}{*}{ Age (years) } & Hemorrhage & 3 & 3 \\
Onset (months) & $62.3 \pm 8.6^{\mathrm{a}}$ & $69.9 \pm 8.9^{\mathrm{a}}$ \\
\multirow{2}{*}{ Paretic side } & Right & $22.7 \pm 11.9$ & $37.7 \pm 36.6$ \\
& Left & 4 & 8 \\
\hline amean \pm SD, SD: standard deviation, EG: experimental group (n=14), CG: control group \\
$(\mathrm{n}=13)$
\end{tabular}

Table 2. Values of stability limit at pre- and post- test $(\mathrm{N}=27)$

\begin{tabular}{|c|c|c|c|c|c|c|c|}
\hline & & \multicolumn{2}{|c|}{ Length $(\mathrm{cm})$} & \multicolumn{2}{|c|}{ Velocity $(\mathrm{cm} / \mathrm{s})$} & \multicolumn{2}{|c|}{ Distance $(\mathrm{cm})$} \\
\hline & & Pre & Post & Pre & Post & Pre & Post \\
\hline \multirow{2}{*}{ East } & EG & $14.7 \pm 4.4^{\mathrm{a}}$ & $12.8 \pm 7.6^{\mathrm{a}}$ & $1.8 \pm 0.5$ & $1.6 \pm 1.0$ & $3.8 \pm 2.2$ & $3.4 \pm 1.8$ \\
\hline & $\mathrm{CG}$ & $15.8 \pm 5.9$ & $15.9 \pm 4.4$ & $2.0 \pm 0.7$ & $2.0 \pm 0.6$ & $5.0 \pm 2.1$ & $3.8 \pm 2.0^{b}$ \\
\hline \multirow{2}{*}{ North } & EG & $16.0 \pm 6.5$ & $12.2 \pm 5.9^{b}$ & $2.0 \pm 0.8$ & $1.5 \pm 0.7^{b}$ & $2.6 \pm 1.1$ & $1.8 \pm 1.2^{b}$ \\
\hline & $\mathrm{CG}$ & $16.0 \pm 7.9$ & $13.8 \pm 6.1^{\mathrm{b}}$ & $2.0 \pm 1.0$ & $1.7 \pm 0.8^{b}$ & $3.5 \pm 1.7$ & $3.2 \pm 1.5^{\mathrm{c}}$ \\
\hline \multirow{2}{*}{ South } & EG & $14.3 \pm 6.7$ & $12.9 \pm 6.1$ & $1.8 \pm 0.8$ & $1.6 \pm 0.8$ & $2.0 \pm 1.0$ & $1.3 \pm 0.8^{b}$ \\
\hline & $\mathrm{CG}$ & $15.8 \pm 7.1$ & $13.7 \pm 4.5$ & $2.0 \pm 0.9$ & $1.7 \pm 0.6^{b}$ & $2.1 \pm 0.8$ & $1.9 \pm 0.7^{\mathrm{c}}$ \\
\hline \multirow{2}{*}{ West } & EG & $15.8 \pm 6.5$ & $14.9 \pm 9.5$ & $2.0 \pm 0.8$ & $1.9 \pm 1.2$ & $3.7 \pm 1.6$ & $2.4 \pm 1.6^{b}$ \\
\hline & $\mathrm{CG}$ & $16.1 \pm 5.4$ & $14.3 \pm 6.0$ & $2.0 \pm 0.7$ & $1.8 \pm 0.8$ & $4.6 \pm 1.9$ & $4.1 \pm 1.5^{\mathrm{c}}$ \\
\hline
\end{tabular}

${ }^{a}$ mean \pm SD; SD: standard deviation; ${ }^{b} p<0.05$ within a group; ${ }^{c} p<0.05$ between groups; $E G$ : experimental group ( $\left.n=14\right)$; CG: control group $(\mathrm{n}=13)$

\section{SUBJECTS AND METHODS}

This study was conducted from June to July, 2015 with 27 post-stroke patients who were hospitalized in D rehabilitation hospital in Daejeon city, South Korea. The subjects were randomly divided into 2 groups: the experimental group (EG, $\mathrm{n}=14)$, and the control group $(\mathrm{CG}, \mathrm{n}=13)$. The demographics and clinical characteristics of the participants are shown in Table 1 .

The criteria for inclusion in this study were: post-stroke patients with hemiplegia, at least 6 months since onset, and the ability to communicate and understand the instructions being given. Patients with the following were excluded: peripheral neuropathy, musculoskeletal disease, and dementia. All subjects signed the written informed consent before participating in the study.This study followed the ethical principles of the Declaration of Helsinki. The shoulder stabilizing exercise intervention was performed by the EG, and conventional physical therapy was administered to the CG for 30 minutes, 3 times a week for 4 weeks. The procedure of the intervention was as follows: 1) sit on a chair, 2) place the pelvis and the spine in the neutral position, 3) put the less affected arm on a support table, 4) unloading of the affected scapular for scapular setting, 5) lateral rotation of the arm with the elbow flexed at about 90 degrees, 6) reaching out with the arm in different directions moving the scapula out as far as possible. Virtual reality (RM, BioRescue -AP 1153, France) was used as an assessment tool. All data were analyzed using SPSS version 18 (Statistical Package for the Social Science). The $\chi^{2}$ test was used to examine differences in the general characteristics of the subjects. The Kolmogorov-Smirnov test showed the data had a normal distribution in this study, therefore the paired t-test was used to test the significance of intra-group differences, and the independent t-test was used to test the significance of inter-group differences. All data are presented as the mean with standard deviation (SD). The level of significance was $\mathrm{p}=0.05$ in all statistical tests.

\section{RESULTS}

After the intervention, there were significant differences in the distances moved in the anteroposterior and mediolateral directions in the EG. The length and velocity of movement were reduced after the intervention in the EG and CG. There were significant differences in the distances moved in the anteroposterior and mediolateral directions between the two groups. The results of the length, velocity and distance are shown in Table 2. The sway path lengths of the subjects in the Romberg test 
Table 3. Values of the Romberg test at pre- and post-test $(\mathrm{N}=27)$

\begin{tabular}{lccccccccc}
\hline & \multicolumn{4}{c}{ Length $(\mathrm{cm})$} & \multicolumn{3}{c}{ Velocity $(\mathrm{cm} / \mathrm{s})$} \\
& \multicolumn{3}{c}{ EO } & \multicolumn{2}{c}{ EC } & \multicolumn{3}{c}{ EO } & \multicolumn{2}{c}{ EC } \\
& EG & CG & EG & CG & EG & CG & EG & CG \\
\hline Pre & $22.2 \pm 6.2^{\text {a }}$ & $7.8 \pm 2.1^{\text {a }}$ & $43.5 \pm 12.1$ & $15.8 \pm 4.2$ & $0.4 \pm 0.1$ & $0.2 \pm 0.0$ & $0.8 \pm 0.2$ & $0.2 \pm 0.1^{\mathrm{b}}$ \\
Post & $15.0 \pm 4.2$ & $16.2 \pm 4.3$ & $29.5 \pm 8.2$ & $17.0 \pm 4.5$ & $0.3 \pm 0.1$ & $0.3 \pm 0.1$ & $0.5 \pm 0.1$ & $0.3 \pm 0.1$ \\
\hline
\end{tabular}

${ }^{\mathrm{a}}$ mean \pm SD; SD: standard deviation; ${ }^{b} \mathrm{p}<0.05$ between groups; EG: experimental group $(\mathrm{n}=14)$; CG: control group $(\mathrm{n}=13)$; EO: eyes open; EC: eyes closed

were reduced under both the eyes open (EO) and eyes closed (EC) conditions in the EG. There was no significant variation in sway velocity of the EG and CG. The results of the Romberg test are shown in Table 3.

\section{DISCUSSION}

The upward rotation angle of the scapula in resting, measured in a previous study, reflected the strength of the trapezius, serratus anterior, and supraspinatus, and activation of these muslces makes the scapula elevate and rotate upward ${ }^{6}$. Abductors and external rotators are more important than internal rotators for providing stability to the shoulder joint, and manual resistance exercises should be applied for strengthening these muscles rahter than other types of exercise ${ }^{7)}$. Resistance exercises tend to re-educate the stability and tone the muscles around the scapula for better postural alignment and may influence the recruitment, firing rate and synchrony of the motor neurons ${ }^{8,9)}$. Scapular muscle strength is necessary to increase the postural stability of the proximal trunk and shoulder complex. Moreover, it was demonstrated in a previous study that the spinal alignment showed better improvement after scapular muscle strengthening exercise. Spinal lateral deviation is negatively correlated with the peak force of the external rotators in the shoulder complex ${ }^{4}$. A previous case study reported that global postural re-education exercises for muscles in the scapular and pelvic girdles had greater influence on scapular position and lateral deviation of the spine, and this was attributed to better spinal alignment. In addition, the rotator cuff muscles were influenced not only by scapular alignment but also by core stability, even though these muscles are not attached to the rib cage or spinal column ${ }^{10)}$. In this study, as in a previous study, which reported there was better core stability after shoulder strengthening exercises, the EG were able to move the center of gravity (COG) directly moved in the anteroposterior and mediolateral directions. Although the velocity of the movements was reduced, this can be explained by the subjects trying to specifically control their COG within their base of support. The reduced distances to each terminal point in all directions support this explanation for the EG. Moreover, the Romberg test also showed reduced sway path lengths, both with EO and $\mathrm{EC}$, in the EG. Therefore, the shoulder stabilizing exercise influenced balance through activation of muslces around the shoulder and trunk.

\section{REFERENCES}

1) Hatakenaka M, Miyai I, Sakoda S, et al.: Proximal paresis of the upper extremity in patients with stroke. Neurology, 2007, 69: 348-355. [Medline] [CrossRef]

2) Oujamaa L, Relave I, Froger J, et al.: Rehabilitation of arm function after stroke. Literature review. Ann Phys Rehabil Med, 2009, 52: 269-293. [Medline] [CrossRef]

3) Hardwick DD, Lang CE: Scapular and humeral movement patterns of people with stroke during range-of-motion exercises. J Neurol Phys Ther, 2011, 35: 18-25. [Medline] [CrossRef]

4) Awad A, Shaker H, Shendy W, et al.: Effect of shoulder girdle strengthening on trunk alignment in patients with stroke. J Phys Ther Sci, 2015, 27: 2195-2200. [Medline] [CrossRef]

5) Garland SJ, Willems DA, Ivanova TD, et al.: Recovery of standing balance and functional mobility after stroke. Arch Phys Med Rehabil, 2003, 84: 1753-1759. [Medline] [CrossRef]

6) Genthon N, Vuillerme N, Monnet JP, et al.: Biomechanical assessment of the sitting posture maintenance in patients with stroke. Clin Biomech (Bristol, Avon), 2007, 22: 1024-1029. [Medline] [CrossRef]

7) Mottram SL: Dynamic stability of the scapula. Man Ther, 1997, 2: 123-131. [Medline] [CrossRef]

8) Folland JP, Williams AG: The adaptations to strength training: morphological and neurological contributions to increased strength. Sports Med, 2007, 37: 145-168. [Medline] [CrossRef]

9) Falvo MJ, Sirevaag EJ, Rohrbaugh JW, et al.: Resistance training induces supraspinal adaptations: evidence from movement-related cortical potentials. Eur J Appl Physiol, 2010, 109: 923-933. [Medline] [CrossRef]

10) Escamilla RF, Yamashiro K, Paulos L, et al.: Shoulder muscle activity and function in common shoulder rehabilitation exercises. Sports Med, 2009, 39: 663-685. [Medline] [CrossRef] 